\title{
A Mild Method for Regioselective Labeling of Aromatics with Radioactive lodine
}

Rønnest, Mads Holger; Nissen, Felix; Pedersen, Palle Jacob; Larsen, Thomas Ostenfeld; Mier, Walter; Clausen, Mads Hartvig

Published in:

European Journal of Organic Chemistry

Link to article, DOI:

10.1002/ejoc.201300419

Publication date:

2013

Document Version

Publisher's PDF, also known as Version of record

Link back to DTU Orbit

Citation (APA):

Rønnest, M. H., Nissen, F., Pedersen, P. J., Larsen, T. O., Mier, W., \& Clausen, M. H. (2013). A Mild Method for Regioselective Labeling of Aromatics with Radioactive lodine. European Journal of Organic Chemistry, 2013(19), 3970-3973. https://doi.org/10.1002/ejoc.201300419

\section{General rights}

Copyright and moral rights for the publications made accessible in the public portal are retained by the authors and/or other copyright owners and it is a condition of accessing publications that users recognise and abide by the legal requirements associated with these rights.

- Users may download and print one copy of any publication from the public portal for the purpose of private study or research.

- You may not further distribute the material or use it for any profit-making activity or commercial gain

- You may freely distribute the URL identifying the publication in the public portal 


\title{
A Mild Method for Regioselective Labeling of Aromatics with Radioactive Iodine
}

\author{
Mads H. Rønnest, ${ }^{[a, b]}$ Felix Nissen, ${ }^{[c]}$ Palle J. Pedersen, ${ }^{[a]}$ Thomas O. Larsen, ${ }^{[b]}$ \\ Walter Mier, ${ }^{[c]}$ and Mads H. Clausen ${ }^{*[a]}$
}

Keywords: Isotopic labeling / Radiochemistry / Medicinal chemistry / Iodine / Silanes / Thallium

A novel technique to label ortho-, meta-, and para-trimethylsilyl-substituted aryl substituents with radioactive iodide is described. The method takes advantage of the ipso-directing and activating properties of trimethylsilyl substituents on the arenes. The method was demonstrated on a griseofulvin ana- logue with promising anticancer properties and on lidocaine, a widely used local anesthetic drug. Treatment of a trimethylsilyl precursor with $\mathrm{Tl}\left(\mathrm{OCOCF}_{3}\right)_{3}$ followed by $\mathrm{Na}^{125}$ I consistently afforded radioactive purities over $95 \%$ in all cases.

\section{Introduction}

Methods for labeling of organic molecules with radioactive isotopes of iodine, such as ${ }^{123} \mathrm{I},{ }^{125} \mathrm{I}$, and ${ }^{131} \mathrm{I}$, are important for medical applications. Iodinated drug candidates are used for screening antibodies in radioimmunoassays (RIAs) ${ }^{[1]}$ and in preclinical ADME (absorption, distribution, metabolism, and excretion) studies. ${ }^{[2]}$ Owing to emission of gamma radiation, iodinated radiopharmaceuticals are also used in scintigraphic imaging for disease diagnostics, ${ }^{[3]}$ for example, in the localization of tumors by use of meta-iodobenzylguanidine (MIBG) labeled with ${ }^{123} \mathrm{I}^{\left[{ }^{4]}\right.}$

The iodination of aromatics can be achieved by different methods, ${ }^{[5]}$ and the choice of labeling method depends very much on the substrate. Many of the most widely used labeling techniques involve the use of oxidizing agents such as chloramine $\mathrm{T},{ }^{[6]}$ iodogen,,${ }^{[7]}$ and lactoperoxidase $;{ }^{[8]}$ however, these methods suffer from low selectivity and are restricted to activated aromatics. The regioselectivity (labeling position) can be hard to control and to some extent so can the degree of labeling (the number of iodine atoms introduced). Depending on the substrate, this can result in the formation of numerous side products, ${ }^{\left[{ }^{5}\right]}$ which then have to be purified, often by tedious chromatographic methods. ${ }^{[9]}$ Further-

[a] Department of Chemistry, Center for Nanomedicine and Theranostics,

Kemitorvet 207, 2800 Kgs. Lyngby, Denmark

Fax: +45-4593-3968

E-mail: mhc@kemi.dtu.dk

Homepage: http://www.organic.kemi.dtu.dk/Research/mhcl

[b] Department of Systems Biology, Center for Microbial Biotechnology,

Søltofts Plads, Building 221, 2800 Kgs. Lyngby, Denmark

[c] Department of Nuclear Medicine, University Hospital Heidelberg,

69120 Heidelberg, Germany

Supporting information for this article is available on the WWW under http://dx.doi.org/10.1002/ejoc.201300419. more, many iodination methods are only applicable to activated aromatics, such as tyrosine in labeling of peptides and proteins. ${ }^{[5]}$

Therefore, there is a need for a broader collection of selective iodination techniques that can be performed under mild conditions. Our interest in iodination techniques arose during our search for potent analogues of the natural product griseofulvin (1) ${ }^{[10]}$ that can inhibit centrosomal clustering in cancer cells. ${ }^{[1]}$ GF-15 (compound 2, Figure 1) was identified as one of the most active analogues, ${ }^{[12]}$ and for in vivo biodistribution and half-life studies we became interested in ${ }^{125}$ I labeling of $2^{[13]}$ As the activities of the three iodinated isomers of $\mathbf{2}$ (i.e., $\mathbf{8 - 1 0}$, see Scheme 1) in a phenotypic whole-cell assay for multipolarity ${ }^{[1]}$ are markedly different (data not shown), we found it crucial to apply a method that would afford a single regioisomer and thus enable us to access the ortho- (i.e., 8), meta- (i.e., 9), and paraiodo (i.e., 10) isomers.

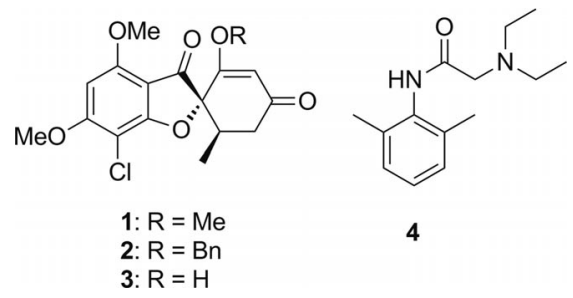

Figure 1. Structures of griseofulvin (1), its analogue GF-15 (2), griseofulvic acid (3), and lidocaine (4).

McKillop et al. ${ }^{[14]}$ have introduced a method for the iodination of small aryl-containing organic molecules by the use of $\mathrm{Tl}\left(\mathrm{OCOCF}_{3}\right)_{3}$ and iodide. Mechanistically, the thallated aromatics are formed by direct electrophilic metalation of the aryl ring with $\mathrm{Tl}\left(\mathrm{OCOCF}_{3}\right)_{3}$, after which ligand exchange with iodide followed by ipso substitution creates the aryl-iodine bond. Whereas the reaction of the 


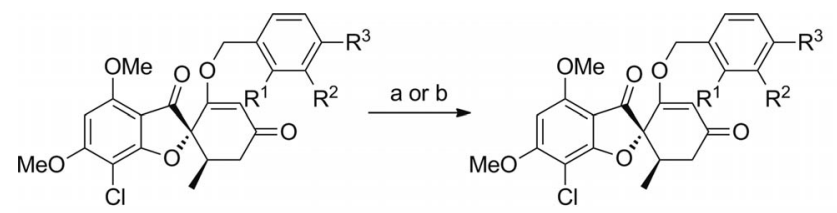

5: $\mathrm{R}^{1}=\mathrm{SiMe}_{3} ; \mathrm{R}^{2}, \mathrm{R}^{3}=\mathrm{H}$ 6: $\mathrm{R}^{2}=\mathrm{SiMe}_{3} ; \mathrm{R}^{1}, \mathrm{R}^{3}=\mathrm{H}$ 7: $\mathrm{R}^{3}=\mathrm{SiMe}_{3} ; \mathrm{R}^{1}, \mathrm{R}^{2}=\mathrm{H}$

8: $R^{1}=I ; R^{2}, R^{3}=H(44 \%)$

9: $R^{2}=I ; R^{1}, R^{3}=H(8 \%)$

10: $R^{3}=I ; R^{1}, R^{2}=H(80 \%)$

8: $R^{1}={ }^{125} ; ; R^{2}, R^{3}=H(R C P>95 \%)$

9: $R^{2}=125 ; \quad R^{1}, R^{3}=H(R C P>95 \%)$

10: $R^{3}={ }^{125} ; ; R^{1}, R^{2}=H(R C P>95 \%)$

Scheme 1. Labeling of griseofulvin analogues with ${ }^{127} \mathrm{I}$ and ${ }^{125} \mathrm{I}$. Reagents: (a) $\mathrm{Tl}\left(\mathrm{OCOCF}_{3}\right)_{3}, \mathrm{NaI}, \mathrm{MeCN} / \mathrm{TFA}$ (7:3); (b) $\mathrm{Tl}(\mathrm{OC}-$ $\left.\mathrm{OCF}_{3}\right)_{3}, \mathrm{Na}^{125} \mathrm{I}, \mathrm{MeCN} / \mathrm{TFA}(7: 3) . \mathrm{RCP}=$ radiochemical purity.

aryl thallium(III) bis(trifluoroacetate) intermediate with iodide affords solely the ipso-substituted product, ${ }^{[15]}$ the initial thallation can yield mixtures of the three possible regioisomers, depending on the substrate and conditions. ${ }^{[16]}$ The labeling is typically performed in pure trifluoroacetic acid (TFA). ${ }^{[16,17]}$ In the case of substrates that cannot tolerate these conditions, addition of a cosolvent, such as $\mathrm{MeCN}$, can usually prevent substrate degradation. ${ }^{[16]}$ However, addition of a cosolvent also lowers the reactivity, which means that deactivated aromatics can be challenging to label. When we exposed griseofulvin analogue 2 to the reaction conditions $\left[\mathrm{Tl}\left(\mathrm{OCOCF}_{3}\right)_{3}\right.$ in neat TFA], hydrolysis to form griseofulvic acid (3, Figure 1) took place within minutes, but when milder conditions $\left[\mathrm{Tl}\left(\mathrm{OCOCF}_{3}\right)_{3}\right.$ in $\mathrm{MeCN} / \mathrm{TFA}, 7: 3]$ were used, no conversion of 2 was observed.

\section{Results and Discussion}

In continuation of the work by McKillop et al., a regioselective variant of the iodination method was published by Bell et al. ${ }^{[18]}$ They discovered that trimethylsilyl (TMS)-substituted aryls, such as 3-trimethylsilyltoluene, undergo ipso substitution when treated with $\mathrm{Tl}\left(\mathrm{OCOCF}_{3}\right)_{3}$, whereas none of the other regioisomers are formed above trace levels. Furthermore, the introduction of the TMS group increases the reactivity of the aromatic system, whereby less activated aryls can be thallated and iodinated. The application of this iodination technique has, to the best of our knowledge, only been used scarcely and only with nonradioactive iodide. Therefore, motivated by the work of Bell et al. ${ }^{[18]}$ we hypothesized that by use of TMS-aryls 5, 6, and 7 (see Scheme 1), incorporation of radioactive iodide into griseofulvin analogue 2 would be possible via the corresponding thallated intermediates. To further elucidate the scope of the technique, iodination of lidocaine (4, Figure 1$)$ was also investigated. Lidocaine (4) is a widely used local anesthetic drug, and iodination of this drug has previously been explored by El-Moselhy et al. ${ }^{[19]}$

The TMS-benzyl analogues of griseofulvin (i.e., 5-7, Scheme 1) were synthesized from the corresponding TMSbenzyl alcohols by using known procedures (see the Supporting Information). ${ }^{[12]}$
Initially, the labeling procedure was tested with nonradioactive iodide. The three mono-TMS-analogues of griseofulvin (i.e., 5-7) were dissolved in MeCN/TFA (7:3) and then subjected to $\mathrm{Tl}\left(\mathrm{OCOCF}_{3}\right)_{3}$ (2 equiv.) for $30 \mathrm{~min}$ after which $\mathrm{NaI}$ (4 equiv.) was added, and the reaction mixtures were stirred for $2 \mathrm{~min}$ and then quenched by the addition of a saturated aqueous solution of $\mathrm{Na}_{2} \mathrm{CO}_{3}$. Gratifyingly, LCMS analysis of the reaction mixtures showed that the corresponding iodides were formed as the only product, whereas some unreacted starting material was also detected. Iodinated products $\mathbf{8}, \mathbf{9}$, and $\mathbf{1 0}$ were isolated by column chromatography in 44,8 , and $80 \%$ yield, respectively. The low isolated yield of $\mathbf{9}$ is due to low conversion of starting material 6 into the thallated intermediate, which presumably is a consequence of the meta-substitution pattern in $\mathbf{6}$. However, for use in labeling with radioactive iodide the low conversion in the electrophilic aromatic thallation is not critical, as radioactive iodide is used in substoichiometric amounts, whereby it becomes the limiting reagent anyway (vide infra). The formation of only the ipso-substituted product was confirmed by comparison of the NMR spectra and the LC-MS data for iodides $\mathbf{8}-\mathbf{1 0}$, which were made through a conventional route from the corresponding iodobenzyl alcohols (see the Supporting Information). Furthermore, the identity and uniformity of the products were verified by their retention times in HPLC analyses.

Additionally, the iodination of 7 (para-TMS) was tested with a lower amount of TFA (10 and 20\% TFA in MeCN) but still with the use of 2 equiv. $\mathrm{Tl}\left(\mathrm{OCOCF}_{3}\right)_{3}$ and an excess amount of NaI. At $10 \%$ TFA, the iodo product was only observed in trace amounts (LC-MS analysis), whereas at $20 \%$ TFA, the conversion to the iodo product was $<20 \%$, and this demonstrates the necessity of TFA for the reaction to occur. It was also investigated how the reaction was affected by using lower amounts of $\mathrm{Tl}\left(\mathrm{OCOCF}_{3}\right)_{3}(0.9$ equiv. $)$ in MeCN/TFA (7:3), and under these conditions, the conversion of 5, 6, and $\mathbf{7}$ into the iodo products was 1,5 , and $20 \%$, respectively. In complete absence of $\mathrm{Tl}\left(\mathrm{OCOCF}_{3}\right)_{3}$, no conversion of the starting material took place, and this underlines that protodesilylation does not occur under the conditions.

With the promising results from the iodination with ${ }^{127}$ I in hand, we went on with ${ }^{125}$ I labeling, in which the radioactive iodine was the limiting reagent. The labeling was performed by dissolving TMS precursors 5, $\mathbf{6}$, and $\mathbf{7}$ in $\mathrm{MeCN} /$ TFA (7:3) after which the thallation was initiated by addition of $\mathrm{Tl}\left(\mathrm{OCOCF}_{3}\right)_{3}(0.5$ equiv.). The reaction mixture was stirred for $2 \mathrm{~min}$ at $20^{\circ} \mathrm{C}, \mathrm{Na}^{125} \mathrm{I}\left(1.7-3.4 \times 10^{-4}\right.$ equiv. was added, and HPLC analysis was performed after $30 \mathrm{~s}$. As evident from the chromatograms in Figure 2, the radiochemical purity (RCP) by HPLC for all three radioiodinations was $>95 \%$. The identity of the labeled compounds was confirmed by coelution with nonradioactive reference compounds in the HPLC analyses (detected in the UV channel).

TMS analogue 11 (see Scheme 2) of lidocaine (4) was synthesized in three steps from commercially available 4bromo-2,6-dimethylaniline. For this substrate, we took ad- 


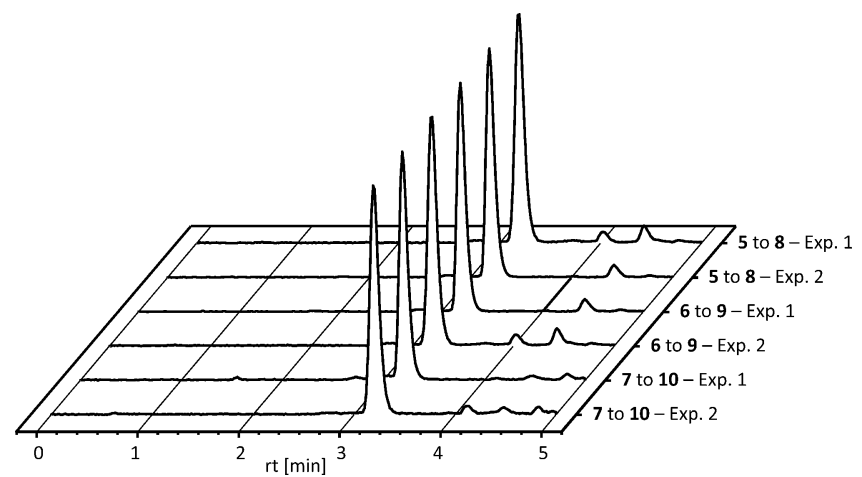

Figure 2. HPLC analysis (radio channel) of the ${ }^{125} \mathrm{I}$ labeling of griseofulvin analogues 5, 6, and $\mathbf{7}$ into corresponding iodides $\mathbf{8 , 9}$, and 10, respectively.

vantage of one of the mild methods available for the introduction of a TMS group: the palladium-catalyzed crosscoupling of an aryl halide with hexamethyldisilane ${ }^{[20]}$ (see the Supporting Information). The test iodination with $\mathrm{Na}^{127} \mathrm{I}$ ( 0.5 equiv. $)$ with the use of 0.5 equiv. $\mathrm{Tl}\left(\mathrm{OCOCF}_{3}\right)_{3}$ in MeCN/TFA (7:3) gave desired iodinated lidocaine $\mathbf{1 2}$ (full conversion by LC-MS, see Supporting Information). The iodination also occurred if $\mathrm{MeCN} / \mathrm{TFA} / \mathrm{H}_{2} \mathrm{O}$ (6:3:1) was used as the solvent mixture, which demonstrates that $\mathrm{H}_{2} \mathrm{O}$ is tolerated in the reaction (see the Supporting Information for LC-MS analysis). Subjection of lidocaine (4) with no TMS group to the iodination conditions gave no iodide incorporation, whereas when neat TFA was used as the solvent, iodination was observed, and this verifies that under mild reaction conditions the TMS group is crucial for the reactivity of the aromatic ring. Performing the reaction with $\mathbf{1 1}$ and $\mathrm{Na}^{125}$ I gave the desired incorporation of ${ }^{125} \mathrm{I}$ with high radiochemical purity as shown for two independent experiments in Figure 3.

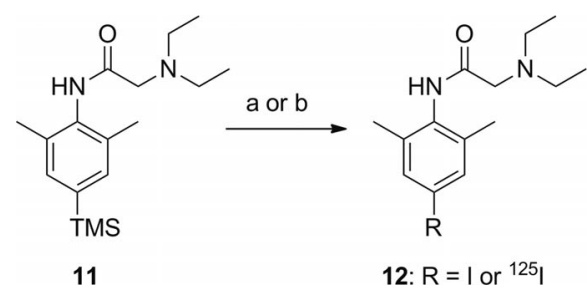

Scheme 2. Iodination of TMS-lidocaine analogue 11. Reagents: (a) $\mathrm{Tl}\left(\mathrm{OCOCF}_{3}\right)_{3}, \quad \mathrm{NaI}, \quad \mathrm{MeCN} / \mathrm{TFA}$ (7:3); (b) $\mathrm{Tl}\left(\mathrm{OCOCF}_{3}\right)_{3}$, $\mathrm{Na}^{125} \mathrm{I}, \mathrm{MeCN} / \mathrm{TFA}(7: 3)$.

The use of TMS-aryls as precursors for radioiodination has been reported previously. ${ }^{[5,21]}$ However the reported reaction conditions are rather harsh (e.g., $\mathrm{NaI}$ and tert-butyl hypochlorite or $\mathrm{H}_{2} \mathrm{O}_{2}$ in acetic acid at $60{ }^{\circ} \mathrm{C}$ ) and long reaction times $(>30 \mathrm{~min})$ are needed to obtain reasonable conversion. ${ }^{[21]}$ The need for new procedures that can transform TMS-aryls into their corresponding iodine analogue was recently demonstrated in the attempted iodination of a tomography tracer for the histamine $\mathrm{H} 3$ receptor, for which the use of standard reagents such as chloramine $\mathrm{T}$ and peracid resulted in less than $10 \%$ labeling (see the Supporting Infor-

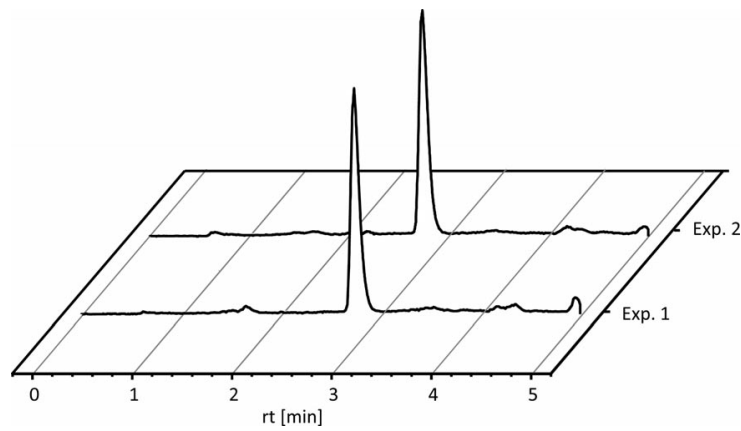

Figure 3. HPLC analysis (radio channel) of the ${ }^{125}$ I labeling of lidocaine analogue $\mathbf{1 1 .}$

mation, Scheme S1, for details). ${ }^{[22]}$ Another popular method for iodination of aromatics through ipso substitution of an activator group is by use of arylstannanes, ${ }^{[5,23]}$ which are typically converted into the corresponding aryl iodide by treatment with $\mathrm{NaI}$ and chloramine $\mathrm{T}$ (or another oxidant such as peracetic acid) in an acidic aqueous environment. Hence, the use of TMS-aryls and $\mathrm{Tl}\left(\mathrm{OCOCF}_{3}\right)_{3}$ is an attractive alternative to arylstannanes, especially for molecules with low water solubility and for substrates that are sensitive to highly acidic environments (such as neat TFA) or oxidizing reagents. It is also noteworthy that the radioiodination with thallium trifluoroacetate is performed for only $30 \mathrm{~s}$, which minimizes the time in which the molecules are subjected to the acidic reaction conditions.

\section{Conclusions}

We were successful in applying the electrophilic aromatic thallation for activation of TMS-aryls in the radioiodination of a potent griseofulvin analogue and lidocaine. Radiochemical purities $>95 \%$ were achieved in all cases. The conditions used are superior to those previously reported, as the iodination proceeds at ambient temperature and in a less acidic environment. Overall, this regioselective iodination method was found to be very convenient, and we envision that this procedure will be a strong alternative to the use of other labeling strategies.

\section{Experimental Section}

Typical Procedure for ${ }^{125}$ I Labeling: The TMS-analogue (70 nmol) was dissolved in MeCN/TFA (7:3, $35 \mu \mathrm{L})$, after which a solution of $\mathrm{Tl}\left(\mathrm{OCOCF}_{3}\right)_{3}$ in MeCN/TFA $(7: 3,15 \mu \mathrm{L}, 2.33 \mathrm{~mm}, 35 \mathrm{nmol})$ was added. The reaction mixture was stirred for $2 \mathrm{~min}$ at $20^{\circ} \mathrm{C}$ and then an aqueous solution of $\mathrm{Na}^{125} \mathrm{I}$ (ca. $0.1 \mu \mathrm{L}, 1-2 \mathrm{MBq}, 12-$ $24 \mathrm{pmol}$ ) was added. After $2 \mathrm{~min}$ of stirring at $20^{\circ} \mathrm{C}$, HPLC analysis was performed.

Safety Note: Thallium compounds are extremely toxic to inhalation, skin contact, and ingestion. Toxicity is cumulative, and $\mathrm{Tl}\left(\mathrm{OCOCF}_{3}\right)_{3}$ should be handled with care in a well-ventilated fume hood.

Supporting Information (see footnote on the first page of this article): Experimental procedures, LC-MS data, and NMR spectra. 


\section{Acknowledgments}

This research was supported by the Danish Research Council (ref. 274-07-0561, support to M. H. R., T. O. L., and M. H. C.), the Danish Cancer Society and Karen Krieger Fonden (support to P. J. P. and M. H. C.), and the German Federal Ministry of Education and Research (BMBF, MoBiTech, support to F. N.)

[1] a) S. J. Goldsmith, Semin. Nucl. Med. 1975, 5, 125-152; b) S. A. Berson, R. S. Yalow, A. Bauman, M. A. Rothschild, K. Newerly, J. Clin. Invest. 1956, 35, 170-190.

[2] a) T. A. Baille, Chem. Res. Toxicol. 2008, 21, 129-137; b) S. Summerfield, P. Jeffrey, Expert Opin. Drug Discovery 2009, 4, 207-218.

[3] J. L. H. Eersels, M. J. Travis, J. D. M. Herscheid, J. Labelled Compd. Radiopharm. 2005, 48, 241-257.

[4] a) G. A. Kaltsas, P. Putignano, J. J. Mukherjee, M. A. Satta, D. G. Lowe, K. E. Britton, J. P. Monson, A. B. Grossman, G. M. Besser, Clin. Endocrinol. 1998, 49, 685-689; b) B. G. Taal, C. A. Hoefnagel, R. A. Valdes Olmos, H. Boot, Eur. J. Cancer 1996, 32, 1924-1932.

[5] a) R. H. Seevers, R. F. Counsell, Chem. Rev. 1982, 82, 575-590; b) V. Vergote, S. Bodé, K. Peremans, H. Vanbree, B. Baert, G. Slegers, C. Burvenich, B. De Spiegeleer, J. Chromatogr. B 2007, 850, 213-220; c) R. Finn, in: Handbook of Radiopharmaceuticals: Radiochemistry and Applications (Eds.: M. J. Welch, C. S. Redvanly), Wiley, Chichester, UK, 2003; d) H. Coenen, J. Mertens, B. Mazieere, Radioiodination Reactions for Radiopharmaceuticals, Springer, Dordrecht, The Netherlands, 2006; e) D. Hubers, P. J. H. Scott, in: RSC Drug Discovery Series No. 15 Biomedical Imaging: The Chemistry of Labels, Probes and Contrast Agents (Ed.: M. Braddock), Royal Society of Chemistry, Cambridge, 2012; f) L. Koehler, K. Gagnon, S. McQuarrie, F. Wuest, Molecules 2010, 15, 2686-2718; g) M. Bourdoiseau, Int. J. Radiat. Appl. Instrum. B 1986, 13, 83-88; h) M. Eisenhut, W. Mier, in: Handbook of Nuclear Chemistry, Springer, Berlin, 2012.

[6] a) W. M. Hunter, F. C. Greenwood, Nature 1962, 194, 495-496; b) F. C. Greenwood, W. M. Hunter, J. S. Glover, Biochem. J. 1963, 89, 114-123.

[7] a) P. J. Fraker, J. C. Speck Jr., Biochem. Biophys. Res. Commun. 1978, 80, 849-857; b) W. Nieuwenhuizen, J. J. Emeis, A. Vermond, P. Kurver, D. Van der Heide, Biochem. Biophys. Res. Commun. 1980, 97, 49-55.

[8] J. J. Marchalonis, Biochem. J. 1969, 113, 299-305.

[9] D. D. Dischino, R. J. Mattson, M. D. Ogan, M. F. Parker, J. P. Yevich, J. Labelled Compd. Radiopharm. 2002, 45, 987-994.
[10] A. E. Oxford, H. Raistrick, P. Simonart, Biochem. J. 1939, 33, 240-248.

[11] B. Rebacz, T. O. Larsen, M. H. Clausen, M. H. Rønnest, H. Löffler, A. D. Ho, A. Krämer, Cancer Res. 2007, 67, 63426350.

[12] a) M. H. Rønnest, B. Rebacz, L. Markworth, A. H. Terp, T. O. Larsen, A. Krämer, M. H. Clausen, J. Med. Chem. 2009, 52 , 3342-3347; b) M. H. Rønnest, M. S. Raab, S. Anderhub, S. Boesen, A. Krämer, T. O. Larsen, M. H. Clausen, J. Med. Chem. 2012, 55, 652-660.

[13] M. S. Raab, I. Breitkreutz, M. H. Rønnest, B. Leber, T. O. Larsen, L. Wagner, S. Anderhub, G. Konotop, P. J. Hayden, K. Podar, J. Fruehaul, F. Nissen, W. Mier, U. Haberkorn, A. D. Ho, H. Goldschmidt, K. C. Anderson, M. H. Clausen, A. Krämer, Cancer Res. 2012, 72, 5374-5385.

[14] a) A. McKillop, J. S. Fowler, M. J. Zelesko, J. D. Hunt, E. C. Taylor, G. McGillivray, Tetrahedron Lett. 1969, 10, 2423-2426; b) A. McKillop, J. S. Fowler, M. J. Zelesko, J. D. Hunt, E. C. Taylor, G. McGillivray, Tetrahedron Lett. 1969, 10, 2427-2430; c) A. McKillop, J. D. Hunt, M. J. Zelesko, J. S. Fowler, E. C. Taylor, G. McGillivray, F. Kienzle, J. Am. Chem. Soc. 1971, 93, 4841-4844.

[15] A. McKillop, J. D. Hunt, J. Organomet. Chem. 1970, 24, 7788.

[16] E. C. Taylor, F. Kienzle, R. L. Robey, A. McKillop, J. D. Hunt, J. Am. Chem. Soc. 1971, 93, 4845-4850.

[17] a) M. Eisenhut, W. E. Hull, A. Mohammed, W. Mier, D. Lay, W. Just, K. Gorgas, W. D. Lehrmann, U. Haberkorn, J. Med. Chem. 2000, 43, 3913-3922; b) C. Nicholl, A. Mohammed, W. E. Hull, B. Bubeck, M. Eisenhut, J. Nucl. Med. 1997, 38, 127-133.

[18] H. C. Bell, J. R. Kalman, J. T. Pinhey, S. Sternhell, Tetrahedron Lett. 1974, 15, 3391-3394.

[19] T. F. El-Moselhy, M. A. El-Kersh, F. Nyberg, R. Hede, M. A. Eldawy, Med. Chem. Res. 1998, 8, 163-170.

[20] a) E. Shirakawa, T. Kurahashi, H. Yoshida, T. Hiyama, Chem. Commun. 2000, 1895-1896; b) E. McNeill, T. E. Barder, S. L. Buchwald, Org. Lett. 2007, 9, 3785-3788; c) S. E. Denmark, J. M. Kallemeyn, Org. Lett. 2003, 5, 3483-3486.

[21] a) D. S. Wilbur, K. W. Anderson, W. E. Stone, A. H. O'Brien Jr., J. Labelled Compd. Radiopharm. 1982, 19, 11711188; b) S. M. Moerlein, H. H. Coenen, J. Chem. Soc. Perkin Trans. 1 1985, 9, 1941-1947.

[22] S. Champion, J. Gross, A. J. Robichaud, S. Pimlott, J. Labelled Compd. Radiopharm. 2011, 54, 674-677.

[23] a) D. E. Seitz, G. L. Tonneson, S. Hellman, R. N. Hanson, J. S Adelstein, J. Organomet. Chem. 1980, 186, C33-C36; b) A. C. Donovan, J. F. Valliant, J. Labelled Compd. Radiopharm. 2011, $54,65-71$.

Received: March 20, 2013 Published Online: May 14, 2013 